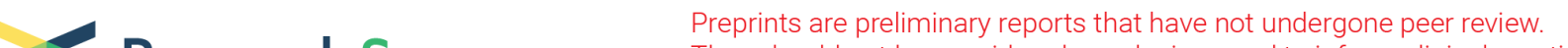 They should not be considered conclusive, used to inform clinical practice, or referenced by the media as validated information.
}

\section{LAG-3 and PD-1/PD-L1 inhibitors might become a promising treatment for small cell lung cancer}

\section{Yi Xu}

Shanghai Pulmonary Hospital

\section{Liping Zhang}

Tongji University Affiliated Shanghai Pulmonary Hospital

\section{Shengyu Wu}

Tongji University Affiliated Shanghai Pulmonary Hospital

\section{Wei Zhang}

Tongji University Affiliated Shanghai Pulmonary Hospital

\section{Yu Liu}

Tongji University Affiliated Shanghai Pulmonary Hospital

\section{Bin Chen}

Tongji University Affiliated Shanghai Pulmonary Hospital

\section{Sha Zhao}

Tongji University Affiliated Shanghai Pulmonary Hospital

\section{Wei Li}

Tongji University Affiliated Shanghai Pulmonary Hospital

\section{Chenglong Sun}

Tongji University Affiliated Shanghai Pulmonary Hospital

\section{Hao Wang}

Tongji University Affiliated Shanghai Pulmonary Hospital

\section{Peixin Chen}

Tongji University Affiliated Shanghai Pulmonary Hospital

\section{Chunyan Wu}

Tongji University Affiliated Shanghai Pulmonary Hospital

\section{Yayi He ( $\sim 2250601 @ q q . c o m)$}

Shanghai Pulmonary Hospital https://orcid.org/0000-0002-2820-9119

\section{Research article}

Keywords: Lymphocyte activing gene-3 (LAG-3), small cell lung cancer (SCLC), immunotherapy

Posted Date: August 18th, 2020 
DOI: https://doi.org/10.21203/rs.3.rs-48482/v1

License: (c) (i) This work is licensed under a Creative Commons Attribution 4.0 International License. Read Full License 


\section{Abstract}

Background Immune therapy has achieved notable success in cancer treatment. A novel immunocheckpoint, Lymphocyte activing gene-3 (LAG-3), has shown promising therapeutic efficacy in non-small cell lung cancer (NSCLC). However, literature about LAG-3 in small cell lung cancer (SCLC) is scarce. We performed statistical analysis to explore LAG-3 expression in SCLC patients, the correlation with programmed death 1 (PD-1) and programmed death ligand 1 (PD-1), the survival predictive significance, and the possibility of becoming an immunotherapeutic checkpoint of SCLC.

Methods In this study, we included 102 patients diagnosed with SCLC. The expression of protein was evaluated by immunohistochemistry (IHC) staining. We performed all the correlation analysis and survival analysis with SPSS software (version 17.0; SPSS, Inc.; Chicago, IL)

Results In SCLC, none tumor cell expressed LAG-3. LAG-3-positive TILs existed in 39.2\% patients. The expression of LAG-3 was remarkably associated to PD-1 and PD-L1 expression on TILs ( $p=0.006, p=$ 0.001 ). LAG-3 was the only prediction for TILs PD-L1 expression (ORs $=0.161,95 \% \mathrm{Cl}: 0.063-0.412, \mathrm{p}<$ 0.01). Although LAG-3-positive patients had relatively longer RFS, LAG-3 expression had no statistically significant differences in predicting prognosis $(p=0.088)$.

Conclusions LAG-3 is an important immune checkpoint closely related to PD-1/PD-L1. There was significant correlation of LAG-3, PD-1, PD-L1 expression. LAG-3 and PD-1/PD-L1 inhibitors might be a promising immune therapy for SCLC.

\section{Background}

Among all cancer types, lung cancer ranks first in both morbidity and mortality and poses an increasingly serious threat to human health ${ }^{[1,2]}$. Approximately $10 \%$ to $15 \%$ cases can be categorized as small-cell lung cancer (SCLC), a cancer type with high growth fraction, high recurrence rate, leading to poor prognosis ${ }^{[3-5]}$. Although chemotherapy is the standard first-line treatment for SCLC ${ }^{[6]}$, resistance to chemotherapy hinders survival prolongation. Therefore, it is an urgency to explore some more effective therapeutic strategies for patients with SCLC.

Some tumor cells with less immunogenicity can escape from immune elimination and developed into cancers. This immune escape can be reversed by suppressing certain immune checkpoints ${ }^{[10]}$. The notable success of some immune checkpoints inhibitors in treating cancers has been reported ${ }^{[11,12]}$. The PD-1/PD-L1 inhibitors has been approved effective for treating NSCLC. They can also significantly prolong survival of SCLC patients combined with the first-line chemotherapy ${ }^{[13-16]}$.

Whereas the insensitivity to PD-1/PD-L1 blockade hinders its extended use ${ }^{[17,18]}$, some other therapeutic checkpoints are now at the forefront of research, such as LAG-3 ${ }^{[19]}$, a novel immune inhibitory checkpoints $^{[20]}$. 
LAG-3, a surface molecule, also known as CD 223, was identified first in $1990^{[21]}$. LAG-3 is expressed on the membrane of various immunocytes, including tumor-infiltrating lymphocytes (TILs), dendritic cells, T regulatory cells (Treg), natural killer cells, B cells,etc ${ }^{[22,23]}$. As a member of immunoglobulin superfamily, LAG-3 is structurally similar to CD4, with approximately $20 \%$ homology share at DNA sequence ${ }^{[24]}$. LAG-3 shows stronger affinity to human leukocyte antigen II (HLA-II) expressed on antigen presenting cells (APCs) compared to CD4, thereby prohibits the binding of HLA-II with TILs, hindering anti-tumor response ${ }^{[25,26]}$. In HLA-II-positive melanoma tumors, this might pave the way for immune escape with bidirectional function ${ }^{[23]}$.

LAG-3 serves as an essential marker of T cell exhaustion, promoting T-cell apoptosis, inhibiting proliferation, suppressing activation, declining cytokines secretion and increasing tolerance ${ }^{[27,28]}$. Elevated LAG-3-expression was observed on TILs of patients with various solid tumors, such as hepatocellular carcinoma, gastric carcinoma etc, as well as hematologic malignancies ${ }^{[29]}$. Our recent study has found that some NSCLC patients had LAG-3-positive TILs. The expression of LAG-3 can be predicted by PD-1 expression and related to worse prognosis ${ }^{[23]}$.

Scholars regarded that LAG-3 has co-function with PD-L1 and PD-1 ${ }^{[11]}$. In vivo research suggested that T cells would get activated if one of the pathways was blocked, but treatment of blocking both pathways showed even more notable effect ${ }^{[30]}$, better than CTLA-4 blockade for less cytotoxicity ${ }^{[11]}$. Moreover, soluble LAG-3 can possibly be promising anti-cancer vaccine ${ }^{[31]}$.

However, literature is scarce on the LAG-3 expression and how it effects survival in SCLC. To figure this out, we enrolled 102 patients with SCLC, evaluated LAG-3 expression in TILS, conducted survival analysis and correlation analysis of clinic pathological traits and PD-L1, PD-1, LAG-3 expression in this study.

\section{Patients And Methods}

\section{Patients}

We included 102 patients aged from 38 to 81 who were diagnosed as SCLC in Shanghai Pulmonary Hospital from March, 2017 to January, 2019. We reviewed the surgical histology reports of the patients and categorized their lung cancer stages with 8th edition International Association for the Study of Lung Cancer (IASLC) TNM staging system. Fifty four of them received chemotherapy after diagnosis. All participators were competent to provide consent.

\section{IHC Procedure}

Dewaxing tissue slides with xylene, then alcohol, rinsing slides with distilled water. After recovering antigen, background staining reduction, we incubated the primary antibody in the slides at RT for 1 hour. And then, rinsing with PBS, incubating with the HRP-conjugated goat anti-rabbit immunoglobulin $\mathrm{G}$ 
detective antibody at RT for 30 min. Rinsing with PBS, visualizing the antigen with $D A B$, cell nuclear counterstain with hematoxylin and slides mounting. IHC was performed by pathologist Liping Zhang.

\section{Cutoff value determination of surface markers}

We chose a value of at least $5 \%$ as LAG-3 cutoff for the best prediction of recurrence-free survival (RFS). The PD-1 on TILs staining was determined as positive when over $1 \%$. Five percent staining was determined as lower limit of PD-L1 cutoff. The staining of FOXP3, CD3, CD4, CD8 was confirmed as positive when more than $10 \%, 40 \%, 30 \%, 30 \%$ individually.

\section{Statistical analysis}

We conducted correlation analysis and survival analysis with SPSS software (version 17.0; SPSS, Inc.; Chicago, IL). Spearman's rank correlation was applied to calculate relativity of PD-L1, PD-1, LAG-3 expression. We used Chi-square tests to evaluate the relativity of clinicopathological traits and PD-L1, PD1, LAG-3 expression. Logistic regression model was applied to figure out whether LAG-3 made meaningful expression prediction for PD-L1 and PD-1, gender, age, smoking status, lung cancer stage, history of chemotherapy were all included as well. Kaplan-Meier method was implemented to estimate survival curves, and Cox regression model to the correlation analysis on RFS and clinical features, including age, gender, history of chemotherapy, smoking status, staging of lung cancer, PD-L1 on tumor cells, PD-L1 on TILs, PD-1, LAG-3 on TILs and CD3, CD4, CD8, FOXP3. Statistical significance was defined as $\mathrm{P}<0.05$. All statistics were 2 -sided.

\section{Results}

\section{Characterization of LAG-3 expression}

Forty patients had LAG-3-positive TILs (39.2\%). None tumor cells were observed LAG-3-positive.

\section{Patient Characteristics}

The total number of patients enrolled was 102, among them, 84 (82.4\%) were female and 18 (17.6\%) were male. The median age was 62 years old. Fifty eight (56.9\%) of them were non-smoker. Fifty four (52.9\%) patients received chemotherapy before. All the patients were diagnosed as SCLC, with 38 patients $(37.3 \%)$ at stage I, $22(21.5 \%)$ at stage II, and $42(41.2 \%)$ at stage III (Table 1$)$. 


\begin{tabular}{|c|c|}
\hline Characteristic & n (\%) \\
\hline \multicolumn{2}{|l|}{ Sex } \\
\hline Male & $18(17.6 \%)$ \\
\hline Female & $84(82.4 \%)$ \\
\hline \multicolumn{2}{|l|}{ Age, median, y } \\
\hline$<70$ & $79(77.5 \%)$ \\
\hline$\geq 70$ & $23(22.5 \%)$ \\
\hline \multicolumn{2}{|l|}{ Smoking status } \\
\hline Nonsmoker & $58(56.9 \%)$ \\
\hline Smoker & $44(43.1 \%)$ \\
\hline \multicolumn{2}{|l|}{ T stage } \\
\hline 1 & $40(39.2 \%)$ \\
\hline 2 & $47(46.1 \%)$ \\
\hline 3 & $13(12.7 \%)$ \\
\hline 4 & $2(2.0 \%)$ \\
\hline \multicolumn{2}{|l|}{ N stage } \\
\hline 0 & $44(43.1 \%)$ \\
\hline 1 & $23(22.5 \%)$ \\
\hline 2 & $34(33.3 \%)$ \\
\hline 3 & $1(1.1 \%)$ \\
\hline \multicolumn{2}{|l|}{ M stage } \\
\hline 0 & $98(96.1 \%)$ \\
\hline 1 & $4(3.9 \%)$ \\
\hline \multicolumn{2}{|c|}{ Lung cancer stage } \\
\hline $\mathrm{I}$ & $38(37.3 \%)$ \\
\hline II & $22(21.5 \%)$ \\
\hline III & $42(41.2 \%)$ \\
\hline \multicolumn{2}{|l|}{ Chemotherapy } \\
\hline Yes & $54(52.9 \%)$ \\
\hline No & $48(47.1 \%)$ \\
\hline
\end{tabular}


Statistical significance was found between PD-L1 on TILs and LAG-3 expression and $(p=0.001)$. LAG-3 expression was also correlated with on TILs PD-1 expression $(p=0.006)$. No significant correlation existed between PD-L1 on tumor cells and LAG-3 ( $p=0.365)$ (Table 2). Based on univariate and multivariate analysis by logistic regression model, we found that LAG-3 was of a certain significance in the prediction of TILs PD-L1 expression (ORs=0.161, 95\% Cl: 0.063-0.412, $\mathrm{p}<0.01$ ). LAG-3, lung cancer stages and history of chemotherapy all made meaningful predictions for PD-1 expression on TILs (Table 3, Table 4).

\begin{tabular}{|c|c|c|}
\hline \multicolumn{3}{|c|}{$\begin{array}{l}\text { Table 2. Relationships between Different Cheo } \\
\\
\end{array}$} \\
\hline Characteristic & Negative & Positive \\
\hline \multicolumn{3}{|c|}{ PD-1 expression on TILs, $\mathrm{n}(\%)$} \\
\hline Negative & $47(77.1 \%)$ & $14(22.9 \%)$ \\
\hline Positive & $15(36.6 \%)$ & 26 (63.4\%) \\
\hline \multicolumn{3}{|c|}{ PD-L1 expression on tumor cells, $\mathrm{n}(\%)$} \\
\hline Negative & $60(61.2 \%)$ & $38(38.8 \%)$ \\
\hline Positive & $2(50.0 \%)$ & $2(50.0 \%)$ \\
\hline \multicolumn{3}{|c|}{ PD-L1 expression on TILs, n (\%) } \\
\hline Negative & $49(75.4 \%)$ & $16(24.6 \%)$ \\
\hline Positive & $13(34.2 \%)$ & 25 (65.8\%) \\
\hline
\end{tabular}

Univariate and Multivariate Analysis for Prediction of PD-L1 Expression on TILs in SCLC Patients

\begin{tabular}{l|l|l|l|l|l|l|}
\hline & \multicolumn{3}{|l|}{ Univariate } & \multicolumn{2}{l|}{ Multivariate } \\
\hline & ORs & $95 \%$ CI & p Value & ORs & $95 \%$ CI & p Value \\
\hline y vs. $\geq 70 y$ ) & 1.148 & $0.435-3.031$ & 0.781 & & & \\
\hline $\begin{array}{l}\text { ale vs. male) } \\
\text { status (nonsmoker vs. smoker) }\end{array}$ & 0.740 & $0.513-4.039$ & 0.488 & & & \\
\hline II vs. III) & 0.056 & $0.939-1.707$ & 0.507 & & & \\
\hline erapy (yes vs. no) & 1.020 & $0.456-2.279$ & 0.962 & & & \\
\hline egative vs. positive) & 0.159 & $0.066-0.386$ & 0.000 & 0.161 & $0.063-0.412$ & 0.000 \\
\hline
\end{tabular}




\begin{tabular}{l|l|l|l|l|l|l|}
\hline & \multicolumn{2}{|l|}{ Univariate } & \multicolumn{2}{l|}{ Multivariate } \\
\hline s & ORs & $95 \%$ CI & p Value & ORs & $95 \%$ CI & p Value \\
\hline ale vs. male) & 1.059 & $0.409-2.739$ & 0.906 & & & \\
\hline status (nonsmoker vs. smoker) & 1.326 & $0.593-2.964$ & 0.492 & & & \\
\hline -II vs. III) & 1.236 & $0.442-3.455$ & 0.686 & & & \\
\hline $\begin{array}{l}\text { erapy (yes vs. no) } \\
\text { egative vs. positive) }\end{array}$ & 2.339 & $1.010-5.414$ & 0.047 & 3.102 & $1.147-8.390$ & 0.026 \\
\hline
\end{tabular}

\section{Survival analysis}

With Kaplan-Meier analysis, patients who were LAG-3-positive had longer RFS, but there was no significantly statistic difference in comparison with LAG-3-negative patients $(\mathrm{p}=0.088)$ (Figure 1).

\section{Cox Regression Analysis of RFS}

Revealed by the results, lung cancer stage was the only prediction of RFS ( $p=0.021, \mathrm{ORs}=1.885,95 \% \mathrm{Cl}$ : 1.102-3.223). PD-L1, FOXP3, CD3, CD4 and CD8 had significance in Cox regression univariate analysis $(p=0.006,0.004,0.007,0.010,0.007$ individually), but had no significance in multivariate Cox regression (Table 5). 
. Univariate and Multivariate Analysis for RFS in All Patients

\begin{tabular}{|c|c|c|c|c|c|c|}
\hline & Univar & late & & Multiv & riate & \\
\hline$\overline{\mathrm{es}}$ & ORs & $95 \% \mathrm{CI}$ & $\begin{array}{l}\mathrm{p} \\
\text { Value }\end{array}$ & ORs & $95 \% \mathrm{CI}$ & $\begin{array}{l}\mathrm{p} \\
\text { Value }\end{array}$ \\
\hline 70y vs. $\geq 70 y)$ & 1.770 & $\begin{array}{l}0.997- \\
3.143\end{array}$ & 0.051 & & & \\
\hline nale vs. male) & 1.676 & $\begin{array}{l}0.757- \\
3.707\end{array}$ & 0.203 & & & \\
\hline $\begin{array}{llll}\text { g } & \text { status } & \text { (nonsmoker } & \text { vs. }\end{array}$ & 1.693 & $\begin{array}{l}0.990- \\
2.896\end{array}$ & 0.054 & & & \\
\hline [-II vs. III-IV) & 2.111 & $\begin{array}{l}1.243- \\
3.586\end{array}$ & 0.006 & 1.885 & $\begin{array}{l}1.102- \\
3.223\end{array}$ & 0.021 \\
\hline herapy (yes vs. no) & 0.770 & $\begin{array}{l}0.454- \\
1.305\end{array}$ & 0.331 & & & \\
\hline I TILs (negative vs. positive) & 0.981 & $\begin{array}{l}0.959- \\
1.004\end{array}$ & 0.104 & & & \\
\hline $\begin{array}{l}\text { on tumor cells (negative vs. } \\
\text { !) }\end{array}$ & 0.815 & $\begin{array}{l}0.198- \\
3.347\end{array}$ & 0.776 & & & \\
\hline In TILs (negative vs. positive) & 0.417 & $\begin{array}{l}0.223- \\
0.779\end{array}$ & 0.006 & & & \\
\hline )n TILs (negative vs. positive) & 0.612 & $\begin{array}{l}0.348- \\
1.076\end{array}$ & 0.088 & & & \\
\hline gative vs. positive) & 0.480 & $\begin{array}{l}0.281- \\
0.820\end{array}$ & 0.007 & & & \\
\hline gative vs. positive) & 0.450 & $\begin{array}{l}0.245- \\
0.825\end{array}$ & 0.010 & & & \\
\hline gative vs. positive) & 0.400 & $\begin{array}{l}0.206- \\
0.776\end{array}$ & 0.007 & & & \\
\hline$\overline{\text { (negative vs. positive) }}$ & 0.376 & $\begin{array}{l}0.194- \\
0.730\end{array}$ & 0.004 & & & \\
\hline
\end{tabular}

\section{Discussion}

LAG-3 is a novel immune checkpoint, but literature is scarce on its expression in SCLC and the correlation with survival. To our knowledge, this is the first investigation focusing on the possible immunotherapeutic effect of LAG-3 for SCLC.

High LAG-3 expression was reported be observed on TILs in hematologic malignancies and various solid tumors, including hepatocellular carcinoma, gastric cancer, renal cell carcinomas, ovarian cancer and NSCLC ${ }^{[19,29]}$. As is stated above, LAG-3 serves as an essential marker of T cell exhaustion ${ }^{[27,28]}$. TILs are regarded as crucial components in anti-tumor immune response and directly related to the development 
of cancer ${ }^{[32]}$. The function of CD4+, CD $8+T$ cells, DCs, Tregs etc. is regulated by inhibitory and active receptors, remarkably impact cancer immune escape ${ }^{[33]}$. Research indicated that TILs would get activated if PD-1 or LAG-3 pathway alone was blocked, either by antibodies or knocking down ${ }^{[34]}$. From a mechanistic standpoint, LAG-3 blockade is equal to the blockade of the binding between LAG-3 and HLAII molecules. By blocking LAG-3, more HLA-II molecules will bind to TILs, thus enhances anti-tumor responses ${ }^{[35]}$. In our recent study, we found that NSCLC patients with LAG-3-negative TILs had longer survival ${ }^{[23]}$. Built on existing studies, we consider LAG-3 a novel checkpoint of immune-based treatment for cancers. But in SCLC, LAG-3 could not predict survival.

Immune escaping pathways are closely associated with one another ${ }^{[36]}$. LAG-3 has remarkable synergy with PD-1, disrupting immune responses to cancer cells ${ }^{[37]}$. According to existed research, compared with blocking either LAG-3 or PD-1 alone, blocking both pathways showed much more remarkable therapeutic efficacy for cancers ${ }^{[30,34]}$. Another study reported upregulated expression of LAG-3 in patients insensitive to PD-1 blocking treatment, thus combined strategy will improve the prognosis ${ }^{[29,36]}$. This has already been proved in treating melanoma patients with PD-1 inhibitors restriction ${ }^{[38,39]}$.

Given the different impact the above-mentioned checkpoints on NSCLC and SCLC survival, we take the immune mechanism into consideration. Different from over-expressed on variety of tumors including NSCLC, PD-L1 expression is suppressed in SCLC ${ }^{[40]}$. In our study, there were only 4 patients (3.9\%) with PD-L1-positive tumor cells, consistent with previously reported results in an immunohistochemical study of SCLC which found PD-L1-positive tumor cells was lower than $20 \%[41]$. This might be one of the reasons why PD-1/PD-L1 pathway inhibition therapy alone cannot lead to notably improved prognosis in SCLC ${ }^{[42]}$. On the other hand, worse outcomes of SCLC was also considered to linked with higher FOXP3 $+\mathrm{T}$ cells infiltrates $^{[43]}$. Furthermore, the immune microenvironment of SCLC seems to be distinct from that of other solid tumors, for instance, NSCLC ${ }^{[40]}$. In this context, we can infer that combined immunotherapy is especially important in SCLS.

There were some limitations should be taken into consideration. Firstly, this study was a retrospective one. Secondly, the sample size was not large enough and more data are needed to support our indication.

Researchers are moving forward in the investigation of immunotherapy in recent years, aiming to more favorable prognosis for patients with SCLC. It is noteworthy that the characteristics of the SCLC immune microenvironment remain unclear. Researchers are moving forward in LAG-3 function and its interaction with other immunomarkers, yet there are still questions remain to work out. What role does LAG-3 play in the development of SCLC? Which immune checkpoint serves as the key regulator in anti-tumor responses in SCLC? How will immune responses change during the progress of SCLC? Is it possible that different major effector cells are involved in NSCLC and SCLC? Further studies are needed.

\section{Conclusions}


Immunocheckpoints play significant role in tumor immune escape with pathways closely interrelated to one another. Some SCLC patients have LAG-3-positive TILs. LAG-3 is prominently co-functioned with PD1/PD-L1, and one of the meaningful predictions for their expression. Combination of LAG-3 and PD1/PD-L1 inhibitors might become a promising immunotherapy for SCLC.

\section{List Of Abbreviations}

Lymphocyte activing gene-3 (LAG-3), non-small cell lung cancer (NSCLC), small cell lung cancer (SCLC), tumor-infiltrating lymphocytes (TILs)

\section{Declarations}

\section{Ethics approval and consent to participate}

The authors are accountable for all aspects of the work in ensuring that questions related to the accuracy or integrity of any part of the work are appropriately investigated and resolved. This research was approved by the ethics committee of the Shanghai Pulmonary Hospital, Tongji University (No. K20-022). Written consent was given by all patients, and the experiment confirmed with the tenets of the Declaration of Helsinki.

\section{Consent for publication}

Not applicable

\section{Availability of data and materials}

The datasets generated and/or analysed during the current study are not publicly available but are available from the corresponding author on reasonable request.

\section{Competing interests}

The authors declare that they have no competing interests

\section{Funding}

This study was supported in part by a grant of young talents in Shanghai, National Natural Science Foundation of China (81802255), Young Talents in Shanghai (2019QNBJ), 'Dream Tutor' Outstanding Young Talents Program (fkyq1901), Clinical Research Project of Shanghai Pulmonary Hospital (fk18005), Key Discipline in 2019 (oncology), Project of Shanghai Municipal Science and Technology Commission (Project of Municipal Science and Technology Commission), Scientific research project of Shanghai Pulmonary Hospital (fkcx1903), and Shanghai Municipal Commission of Health and Family Planning (2017YQ050). 


\section{References}

[1]Bray F, Ferlay J, Soerjomataram I, et al. Global cancer statistics 2018: GLOBOCAN estimates of incidence and mortality worldwide for 36 cancers in 185 countries. CA Cancer J Clin 2018;68:394-424.

[2]Global Burden of Disease Cancer Collaboration, Fitzmaurice C, Akinyemiju TF, et al. Global, Regional, and National Cancer Incidence, Mortality, Years of Life Lost,Years Lived With Disability, and DisabilityAdjusted Life-Years for 29 Cancer Groups, 1990 to 2016: A Systematic Analysis for the Global Burden of Disease Study. JAMA Oncol 2018;4:1553-68.

[3]van Meerbeeck JP, Fennell DA, De Ruysscher DK: Small-cell lung cancer. Lancet 378:1741-1755, 2011

[4]Travis WD. Advances in neuroendocrine lung tumors. Ann Oncol 2010;21(Suppl 7):vii65-71.

[5]Zakowski MF. Pathology of small cell carcinoma of the lung. Semin Oncol 2003;30:3-8.

[6]Rudin CM, Giaccone G, Ismaila N. Treatment of Small-Cell Lung Cancer: American Society of Clinical Oncology Endorsement of the American College of Chest Physicians Guideline. J Oncol Pract. 2016 Jan;12(1):83-86. doi: 10.1200/JOP.2015.008201. PubMed PMID: 29424581.

[10]Dunn GP, Old LJ, Schreiber RD. The immunobiology of cancer immunosurveillance and immunoediting. Immunity 2004;21:137-48.

[11]Woo SR, Turnis ME, Goldberg MV, et al. Immune inhibitory molecules LAG-3 and PD-1 synergistically regulate T-cell function to promote tumoral immune escape. Cancer Res. 2012;72:917-927.

[12]Takaya S, Saito H, Ikeguchi M. Upregulation of immune checkpoint molecules, PD-1 and LAG-3, on CD4. and CD8. T cells after gastric cancer surgery. Yonago Acta Med. 2015;58:39-44.

[13] He Y, Rozeboom L, Rivard CJ, et al. PD-1, PD-L1 Protein Expression in Non-Small Cell Lung Cancer and Their Relationship with Tumor-Infiltrating Lymphocytes. Med Sci Monit. 2017;23:1208-1216. Published 2017 Mar 9. doi:10.12659/msm.899909

[14]Brahmer JR, Tykodi SS, Chow LQ, Hwu WJ, Topalian SL, Hwu P, Drake CG, Camacho LH, Kauh J, Odunsi K, Pitot HC, Hamid O, Bhatia S, et al. Safety and activity of anti- PD-L1 antibody in patients with advanced cancer. N Engl J Med. 2012; 366:2455-2465.

[15]Horn L, Mansfield AS, Szcz $₫$ sna A, Havel L, Krzakowski M, Hochmair MJ, Huemer F, Losonczy G, Johnson ML, Nishio M, Reck M, Mok T, Lam S, Shames DS, Liu J, Ding B, Lopez-Chavez A, Kabbinavar F, Lin W, Sandler A, Liu SV; IMpower133 Study Group. First-Line Atezolizumab plus Chemotherapy in Extensive-Stage Small-Cell Lung Cancer. N Engl J Med. 2018 Dec 6;379(23):2220-2229. doi: 10.1056/NEJMoa1809064. Epub 2018 Sep 25. PubMed PMID: 30280641. 
[16]Ragavan M, Das M. Systemic Therapy of Extensive Stage Small Cell Lung Cancer in the Era of Immunotherapy. Curr Treat Options Oncol. 2020;21(8):64. Published 2020 Jun 29. doi:10.1007/s11864020-00762-8

[17]Son B, Lee S, Youn H, Kim E, Kim W, Youn B. The role of tumor microenvironment in therapeutic resistance. Oncotarget. 2017; 8:3933-3945.

[18]Zhao X, Subramanian S. Intrinsic Resistance of Solid Tumors to Immune Checkpoint Blockade Therapy. Cancer Res. 2017;77:817-822

[19]He Y, Rivard CJ, Rozeboom L, Yu H, Ellison K, Kowalewski A, Zhou C, Hirsch FR. Lymphocyteactivation gene-3, an important immune checkpoint in cancer. Cancer Sci. 2016; 107:1193-1197.

[20]Marconcini R, Spagnolo F, Stucci LS, Ribero S, Marra E, Rosa F, Picasso V, Di Guardo L, Cimminiello C, Cavalieri S, Orgiano L, Tanda E, Spano L, et al. Current status and perspectives in immunotherapy for metastatic melanoma. Oncotarget. 2018; 9:12452-12470.

[21]Triebel F, Jitsukawa S, Baixeras E, Roman-Roman S, Genevee C, Viegas- Pequignot E, et al. LAG-3, a novel lymphocyte activation gene closely related to CD4. J Exp Med (1990) 171(5):1393-405. doi:10.1084/jem.171.5.1393

[22]Lichtenegger FS, Rothe M, Schnorfeil FM, et al. Targeting LAG-3 and PD-1 to Enhance T Cell Activation by Antigen-Presenting Cells. Front Immunol. 2018;9:385. Published 2018 Feb 27. doi:10.3389/fimmu.2018.00385

[23] He Y, Yu H, Rozeboom L, et al. LAG-3 Protein Expression in Non-Small Cell Lung Cancer and Its Relationship with PD-1/PD-L1 and Tumor-Infiltrating Lymphocytes. J Thorac Oncol. 2017;12(5):814-823. doi:10.1016/j.jtho.2017.01.019

[24]Triebel F, Jitsukawa S, Baixeras E, et al. LAG-3, a novel lymphocyte activation gene closely related to CD4. J Exp Med. 1990;171:1393-1405.

[25]Baixeras E, Huard B, Miossec C, Jitsukawa S, Martin M, Hercend T, et al. Characterization of the lymphocyte activation gene 3-encoded protein. A new ligand for human leukocyte antigen class II antigens. J Exp Med (1992) 176(2):327-37. doi:10.1084/jem.176.2.327

[26]Huard B, Prigent P, Tournier M, Bruniquel D, Triebel F. CD4/major histocom-patibility complex class II interaction analyzed with CD4- and lymphocyte activation gene-3 (LAG-3)-IG fusion proteins. Eur J Immunol (1995) 25(9):2718-21. doi:10.1002/eji.1830250949

[27]Andrews LP, Marciscano AE, Drake CG, et al. LAG3 (CD223) as a cancer immunotherapy target. Immunol Rev 2017;276:80-96. [PubMed: 28258692] 
[28]Nguyen LT, Ohashi PS. Clinical blockade of PD1 and LAG3-potential mechanisms of action. Nat Rev Immunol 2015;15:45-56. [PubMed: 25534622]

[29]Long L, Zhang X, Chen F, et al. The promising immune checkpoint LAG-3: from tumor microenvironment to cancer immunotherapy. Genes Cancer. 2018;9(5-6):176-189. doi:10.18632/genesandcancer.180

[30]Blackburn SD, Shin H, Haining WN, et al. Coregulation of CD8+T cell exhaustion by multiple inhibitory receptors during chronic viral infection. Nat Immunol. 2009;10: 29-37.

[31]Fougeray S, Brignone C, Triebel F. A soluble LAG-3 protein as an immunopotentiator for therapeutic vaccines: preclinical evaluation of IMP321. Vaccine. 2006;24: 5426-5433.

[32]Santoiemma PP, Powell DJ Jr. Tumor infiltrating lymphocytes in ovarian cancer. Cancer Biol Ther. $2015 ; 16: 807-820$.

[33]Xu Y, Wang L, Li W, et al. Killer immunoglobulin-like receptors/human leukocyte antigen class-I, a crucial immune pathway in cancer. Ann Transl Med. 2020;8(5):244. doi:10.21037/atm.2020.01.84

[34]Harris-Bookman S, Mathios D, Martin AM, et al. Expression of LAG-3 and efficacy of combination treatment with anti-LAG-3 and anti-PD-1 monoclonal antibodies in glioblastoma. Int J Cancer. 2018;143(12):3201-3208. doi:10.1002/ijc.31661

[35]Andrews LP, Marciscano AE, Drake CG, et al. LAG3 (CD223) as a cancer immunotherapy target. Immunol Rev 2017;276:80-96. [PubMed: 28258692]

[36]Datar I, Sanmamed MF, Wang J, et al. Expression Analysis and Significance of PD-1, LAG-3, and TIM-3 in Human Non-Small Cell Lung Cancer Using Spatially Resolved and Multiparametric Single-Cell Analysis. Clin Cancer Res. 2019;25(15):4663-4673. doi:10.1158/1078-0432.CCR-18-4142

[37]Matsuzaki J, Gnjatic S, Mhawech-Fauceglia P, Beck A, Miller A, Tsuji T, et al. Tumor-infiltrating NY-ESO1-specific CD8+ T cells are negatively regulated by LAG-3 and PD-1 in human ovarian cancer. Proc Natl Acad Sci U S A. 2010; 107:7875-80. [PubMed: 20385810]

[38]Ascierto PA, Melero I, Bhatia S, Bono P, Sanborn RE, Lipson EJ, Callahan MK, Gajewski T, Gomez-Roca CA, Hodi FS, Curigliano G, Nyakas M, Preusser M, et al. Initial efficacy of anti-lymphocyte activation gene3 (anti-LAG-3; BMS-986016) in combination with nivolumab (nivo) in pts with melanoma (MEL) previously treated with anti-PD-1/PD-L1 therapy. J Clin Oncol. 2017; 35:9520.

[39]Ascierto PA, Bono P, Bhatia S, Melero I, Nyakas M, Svane I, Larkin J, Gomez-Roca CA, Schadendorf D, Dummer R, Marabelle A, Hoeller C, Maurer M, et al. Efficacy of BMS-986016, a monoclonal antibody that targets lymphocyte activation gene-3 (LAG-3), in combination with nivolumab in pts with melanoma. In: ESMO 2017 Congress, Madrid, Spain. Genes \& Cancer 186 
[40]Sabari JK, Lok BH, Laird JH, Poirier JT, Rudin CM. Unravelling the biology of SCLC: implications for therapy. Nat Rev Clin Oncol. 2017;14(9):549-561. doi:10.1038/nrclinonc.2017.71

[41] Yu H, et al. PD-L1 expression by two complementary diagnostic assays and mRNA in situ hybridization in small cell lung cancer. J Thorac Oncol. 2017; 12:110-120. [PubMed: 27639678]

[42]Rivalland G, Walkiewicz $M$, Wright $G$, et al. Small cell lung cancer: the immune microenvironment and prognostic impact of checkpoint expression. J Clin Oncol. 2017;35:abstract 8569.

[43]W. Wang, P. Hodkinson, F. McLaren, et al., Small cell lung cancer tumour cells induce regulatory T lymphocytes, and patient survival correlates negatively with FOXP3+ cells in tumour infiltrate, Int. J. Cancer 131 (2012) E928-937.

\section{Figures}

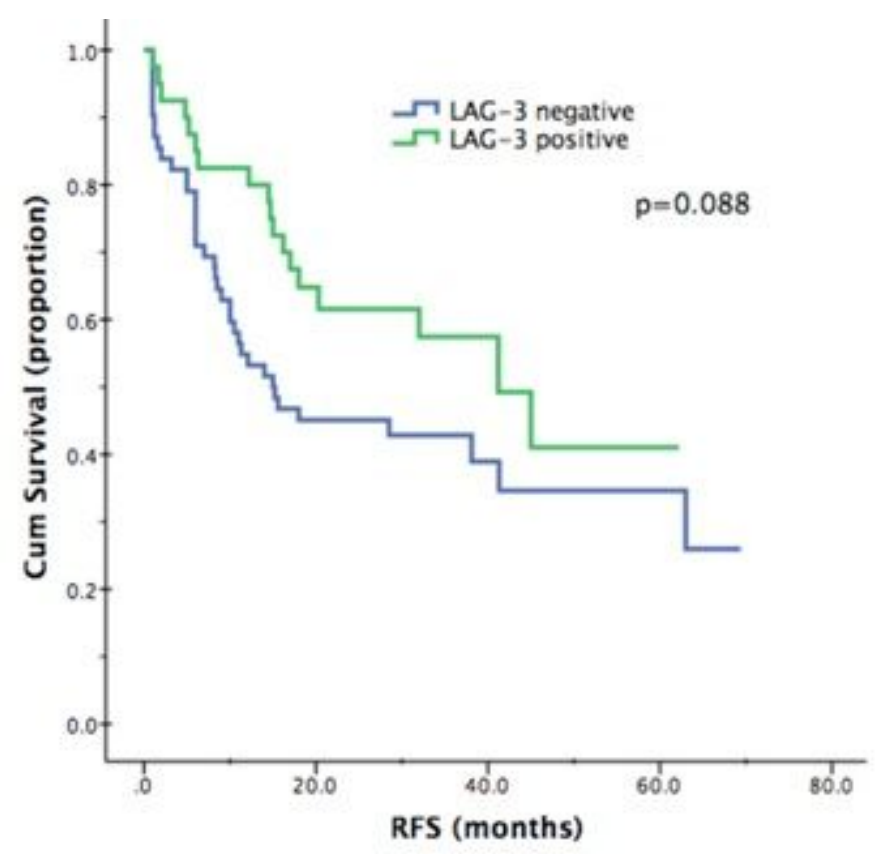

\section{Figure 1}

Lymphocyte activating 3 (LAG-3) recurrence-free survival (RFS) in patients with SCLC. 